\title{
Effect of Dietary Fat Saturation on Plasma Lipoproteins and High Density Lipoprotein Metabolism of the Rhesus Monkey
}

\author{
Kui S. Chong, Robert J. Nicolosi, Richard F. Rodger, Dorothy A. Arrigo, Ruth W. Yuan, \\ John J. MacKey, Steve Georas," and Peter N. Herbert* \\ Harvard Medical School, New England Regional Primate Research Center, Southborough, Massachusetts 01772; ${ }^{*}$ Division of Nutrition \\ and Metabolism, Brown University, Program-in-Medicine, The Miriam Hospital, Providence, Rhode Island 02906
}

\begin{abstract}
Rhesus monkeys were fed corn or coconut oil-based diets for 36 mo to determine effects on the composition of all lipoprotein classes and on the metabolism of high density lipoproteins (HDL). Major findings included the following. (a) Coconut oil feeding increased concentrations of all classes of plasma lipoproteins without altering lipoprotein size, suggesting an increase in particle number. (b) The percentage of saturated fatty acids in the cholesteryl esters (CE) of low density lipoproteins (LDL) and HDL reached $40 \%$ with coconut oil feeding. This value probably constitutes a minimum estimate of the $\mathrm{CE}$ which were of intracellular rather than intraplasmic origin. (c) The CE in LDL and HDL were nearly identical suggesting virtually complete equilibration by the core lipid transfer reaction. The $\mathbf{C E}$ in very low density lipoproteins, in contrast, were significantly more saturated than those in LDL and HDL irrespective of diet. (d) Lower HDL levels on the corn oil diet were associated with higher fractional catabolic rates for both apolipoprotein A-I (0.42 vs. $\left.0.31 \mathrm{~d}^{-1}\right)$ and apolipoprotein A-II (0.45 vs. $\left.0.30 \mathrm{~d}^{-1}\right)$.
\end{abstract}

\section{Introduction}

The quantity and quality of dietary fat affect the concentrations, compositions, and properties of the plasma lipoproteins. Polyunsaturated fat consumption, for example, changes the degree of saturation of lipoprotein lipids, and it has been hypothesized that changes in the physical properties of lipoproteins may alter their metabolic properties $(1,2)$.

There is, however, surprisingly little agreement concerning the effects of dietary saturated and polyunsaturated fat on lipoprotein composition (3). This may relate to inhomogeneity of study populations, differences in effects of specific saturated and polyunsaturated fats, the broad spectrum of analytical methods employed, and effects of diet components other than fat. Moreover, in studies of short duration, transition effects may confound data interpretation.

Polyunsaturated fat-rich diets appear to reduce high density lipoprotein (HDL) concentrations and the mechanism of this effect is uncertain. Shepherd et al. (4) found no change in the fractional catabolic rate of ${ }^{125} \mathrm{I}$-apo A-I when men consumed

Address reprint requests to Dr. Nicolosi, Department of Clinical Sciences, College of Health Professions, University of Lowell, Lowell, MA 01854.

Received for publication 18 November 1985 and in revised form 12 November 1986.

J. Clin. Invest.

(C) The American Society for Clinical Investigation, Inc.

$0021-9738 / 87 / 03 / 0675 / 09 \quad \$ 1.00$

Volume 79, March 1987, 675-683 diets rich in polyunsaturated fat and concluded that the lower apo A-I levels were due to a reduction in the synthetic rate. However, studies in monkeys conducted by Parks and Rudel (5) suggested higher HDL apoprotein catabolic rates in polyunsaturated fat-fed animals.

The studies described in this report were undertaken to clarify several issues related to the effects of dietary fat saturation on lipoprotein composition and metabolism. Old World monkeys were used because their lipoprotein system is highly analogous to humans and because complete control of diet intake is possible. Animals were fed experimental diets for prolonged periods to assure that a steady state had been achieved. Lipoprotein size and chemical composition were measured to determine if effects on lipoprotein lipid concentrations were due to changes in particle lipid content. The specific fatty acids esterified in the major lipid classes of the plasma lipoproteins were analyzed to assess the extent of equilibration mediated by the core lipid transfer protein and to obtain an indirect estimate of the proportion of plasma cholesteryl esters of intracellular and intraplasmic origin. Finally, we sought to determine if the low HDL levels typically observed during consumption of polyunsaturated fat-rich diets were associated with depressed synthesis of the major HDL apoproteins or with augmented catabolism.

\section{Methods}

Animals and diets. Adult female rhesus monkeys (Macaca Mulatta) older than $15 \mathrm{yr}$ were fed two isocaloric diets (Table I) containing $21 \%$ protein, $49 \%$ carbohydrate, and $30 \%$ fat. The fat was supplied as either edible coconut oil or corn oil without added cholesterol (Table II). Coconut oil was used instead of butter or animal fat because it contains no cholesterol, and it alters lipoprotein composition in a manner similar to other saturated fats (6). Coconut oil contains only $0.4 \%$ linoleic acid (18:2), but this appears adequate to prevent essential fatty acid deficiency as judged by body size and growth, clinical appearance, and hematological indices.

Lipoprotein isolation. After an overnight fast, the monkeys were tranquilized with Ketamine (Bristol Laboratories, Veterinary Products, Syracuse, NY) and blood samples drawn from the femoral vein into EDTA-containing tubes to which a final concentration of $0.125 \% \mathrm{~N}$ ethylmaleimide (Sigma Chemical Co., St. Louis, MO) was added to inhibit plasma lecithin:cholesterol acyltransferase (LCAT) ${ }^{1}$ activity. Very low density lipoproteins (VLDL, $d<1.019 \mathrm{~g} / \mathrm{ml}$ ), low density lipoproteins (LDL, $d=1.019-1.063 \mathrm{~g} / \mathrm{ml}$ ) and high density lipoproteins (HDL, $d$ $=1.063-1.21 \mathrm{~g} / \mathrm{ml}$ ) were isolated by sequential ultracentrifugation (7). In some experiments the entire lipoprotein fraction was isolated at $d$ $<1.21 \mathrm{~g} / \mathrm{ml}$. Lipoproteins were dialyzed against $0.9 \% \mathrm{NaCl}, 0.04 \%$ EDTA, and $0.01 \% \mathrm{NaN}_{3}, \mathrm{pH} 7.0$. A column $(2.5 \times 90 \mathrm{~cm})$ containing Bio-Gel A-0.5 m, 200-400 mesh (Bio-Rad Laboratories, Rockville Centre,

1. Abbreviations used in this paper: apo, apolipoprotein; $\mathrm{CE}$, cholesteryl ester; FC, free cholesterol; FCR, fractional catabolic rate; LCAT, lecithin cholesterol acyltransferase; PL, phospholipid; PRO, protein; TG, triglyceride. 
Table I. Composition of Semipurified Monkey Diets

\begin{tabular}{ll}
\hline Ingredient & Anhydrous mix \\
\hline & $g / 100 \mathrm{~g}$ \\
Lactalbumin & 23.60 \\
Dextrin & 27.70 \\
Sucrose & 27.70 \\
Oil (corn or coconut) & 15.10 \\
Inositol & 0.09 \\
Choline chloride & 0.28 \\
Vitamin mix (ref. 10) & 0.50 \\
Salt mix (ref. 10) & 5.03 \\
Alphacel (50 g added to $424 \mathrm{~g}$ of diet) & \\
Agar (2.4\% hot agar solution mixed $1: 1$ with diet & \\
\multicolumn{1}{c}{ mix to form agar cake for feeding) } & \\
\end{tabular}

NY) was used to fractionate the complete plasma lipoprotein fraction (8). The purity of lipoproteins was verified by agarose electrophoresis and $12.5 \%$ sodium dodecyl sulfate (SDS) polyacrylamide gel electrophoresis (PAGE).

Analytical methods. Electron microscopy of isolated lipoprotein fractions was performed as described (9) and particle diameters were estimated by measuring $\sim 150-200$ free-standing particles. Methods employed for thin-layer chromatography and gas liquid chromatography have been detailed previously (10). Total protein was estimated by the method of Lowry (11) using bovine serum albumin (BSA) as a standard with no correction for possible differences in chromogenicity. SDS-PAGE was performed according to Weber and Osborne (12) and isoelectric focusing in polyacrylamide gels as described by Mendel et al. (14). Isoelectric points were determined using a calibration plot of $\mathrm{pH}$ vs the distance traveled by BSA used as a pH marker (14). Cholesterol (15) and triglyceride (16) were quantified using enzymatic methods, and HDLcholesterol was estimated after heparin- $\mathrm{Mn}^{2+}$ precipitation (17) of VLDL and LDL. Unesterified cholesterol was measured by omitting the cholesterol esterase from the enzymatic reagent (15) and phospholipids were quantitated by the method of Bartlett (18).

Preparation of apoproteins and antisera. Rhesus apolipoproteins A-I and A-II were purified to homogeneity using methods previously described in detail (19). Antigen solutions were emulsified with an equal volume of complete Freund's adjuvant and used to immunize rabbits. Antisera produced single precipitin lines on Ouchterlony double diffusion against the respective antigens (not shown).

Apoprotein quantification by radial immunodiffusion. For assay of apo A-I, 3-mm layers of $1 \%(\mathrm{wt} / \mathrm{vol})$ agarose (Bio-Rad Laboratories, Rockville Centre, NY) were prepared on plastic plates in $0.05 \mathrm{M}$ sodium barbital buffer, $\mathrm{pH} 8.2$ containing $1 \%$ (wt/vol) polyethylene glycol (PEG $6,000 \mathrm{~mol} \mathrm{wt}$ ) and $4 \%$ (vol/vol) antiserum. 3-mm diameter wells were made using a well puncher (Bio-Rad Laboratories). Test samples and standards were incubated with an equal volume of $0.2 \mathrm{M}$ sodium cholate/ $1 \%(\mathrm{wt} / \mathrm{vol}) \mathrm{BSA}$ at $37^{\circ} \mathrm{C}$ for $1.5 \mathrm{~h}$. Precipitin rings reached a maximum

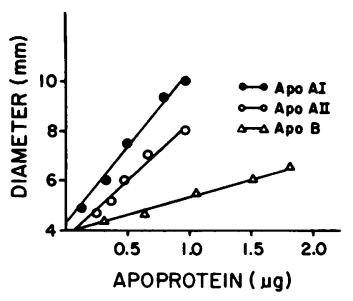

Figure 1. Standard curves from plots of ring diameters obtained by radial immunodiffusion in assays for apo A-I, A-II and LDL (apo B); respective ranges of linearity were 0.12 to 0.94 $\mu \mathrm{g}, 0.24$ to $0.94 \mu \mathrm{g}$, and 0.3 to $1.8 \mu \mathrm{g} /$ sample well.

diameter within $24 \mathrm{~h}$ at room temperature. Ring diameter was measured in $0.1 \mathrm{~mm}$ increments using a microscope equipped with a calibrated ocular. The assay conditions for apo A-II were the same as for apo A-I except that $8 \%$ (vol/vol) antiserum was used. LDL were quantified in $0.5 \%(\mathrm{wt} / \mathrm{vol})$ agarose containing $0.5 \%(\mathrm{vol} / \mathrm{vol})$ antiserum. Standards were purified apoproteins or LDL. Protein content was determined by the method of Lowry (11). Plots of ring diameter as a function of apo A-I, A-II, and LDL dose were linear from 0.12 to $0.94 \mu \mathrm{g}, 0.24$ to 0.94 $\mu \mathrm{g}$, and 0.3 to $1.8 \mu \mathrm{g} /$ sample per well, respectively (Fig. 1). The intraand interassay coefficients of variation for apoproteins A-I, A-II, and LDL, respectively, were 4.1 and $3.0 \%, 2.3$ and $3.5 \%$, and 5.0 and $5.7 \%$.

Metabolic studies. The same rhesus monkeys used in the diet studies were also used for the metabolic studies. Apo A-I metabolism was evaluated in eight animals and apo A-II metabolism in four of these.

HDL were isolated by ultracentrifugation and agarose column chromatography (8) and radioiodinated using the iodine monochloride procedure $(20,21)$. Unbound iodine was removed by dialysis and specific activities ranged from 4.4 to $5.3 \times 10^{4}$ (mean $4.85 \times 10^{4}$ ) cpm $/ \mu \mathrm{g}$ protein. Less than $5 \%$ of the label was in lipid and greater than $95 \%$ of the radioactivity was precipitable with $10 \%$ (wt/vol) trichloroacetic acid. An aliquot of ${ }^{125} \mathrm{I}-\mathrm{HDL}$ was added to $40 \mu \mathrm{g}$ of nonlabeled HDL and apoproteins separated on $12.5 \%$ SDS-PAGE. Gels were stained with Coomassie Blue, and apoprotein bands sliced and ${ }^{125}$ I-radioactivity measured.

Sodium-cholate immunoprecipitation. This method was used to determine radioactivity attributable to apolipoproteins A-I and A-II during lipoprotein kinetic studies. A $0.1-\mathrm{ml}$ aliquot of serum or heparin- $\mathrm{Mn}^{2+}$ supernatant (17) was incubated with $0.1 \mathrm{ml}$ of $0.2 \mathrm{M}$ sodium cholate/ $1 \%(\mathrm{wt} / \mathrm{vol})$ bovine serum albumin for $1 \frac{1 / 2}{\mathrm{~h}}$ at $37^{\circ} \mathrm{C}$. Sufficient rabbit apolipoprotein antisera to yield maximal precipitation was added to this incubation mixture followed by $0.3 \mathrm{ml}$ of $4 \%$ (wt/vol) polyethylene glycol in saline (PEG, $6,000 \mathrm{~mol} \mathrm{wt}$ ). After $16 \mathrm{~h}$ at $4^{\circ} \mathrm{C}$, the mixture was centrifuged at $2,800 \mathrm{rpm}$ for $15 \mathrm{~min}$ at $4^{\circ} \mathrm{C}$ in a TJ-R centrifuge (Beckman Instruments Inc., Fullerton, $\mathrm{CA}$ ). The supernatant was aspirated and the pellet washed twice with $0.3 \mathrm{ml}$ of $4 \%$ (wt/vol) PEG in $0.15 \mathrm{M} \mathrm{NaCl}$. The pellet and supernatant were radioassayed. Nonspecific precipitation measured after addition of nonimmune rabbit serum was usually $<1 \%$. The distribution of radioactivity determined by immunoprecipitation closely agreed with that following SDS-PAGE (Table III).

Preparation of animals for metabolic studies. Monkeys were acclimated to metabolic restraining chairs before study. In unpublished experiments, we found HDL turnover rates in restrained monkeys were identical to those in animals tethered through a swivel system (22). Each morning the appropriate diets in liquid form were fed in a single bolus by orogastric tube to insure inadequate caloric intake. In addition, all

Table II. Fatty Acid Composition (\% Total) of Corn and Coconut Oil Diets

\begin{tabular}{|c|c|c|c|c|c|c|c|c|c|c|}
\hline & \multicolumn{10}{|c|}{ Fatty acid } \\
\hline & $8: 0$ & 10:0 & $12: 0$ & $14: 0$ & $16: 0$ & $18: 0$ & 18:1 & $18: 2$ & $18: 3$ & $\mathrm{P} / \mathrm{S}$ \\
\hline & \multicolumn{10}{|c|}{$\%$ Total } \\
\hline Corn & - & - & $0.4^{*}$ & 0.3 & 11.8 & 2.2 & 24.6 & 59.6 & 1.2 & 4.13 \\
\hline Coconut & 1.0 & 5.8 & 49.2 & 22.5 & 9.6 & 2.2 & 7.5 & 2.2 & - & 0.02 \\
\hline
\end{tabular}

* Values are means of two determinations. 
Table III. The Distribution of Radioactivity in ${ }^{125}$ I-HDL Determined by Immunoprecipitation and PAGE

\begin{tabular}{lccl}
\hline & & \multicolumn{2}{c}{ Radioactivity distribution } \\
\cline { 3 - 4 } Apoproteins & Mass distribution* & $12 \%$ SDS-PAGE & $\begin{array}{l}\text { Cholate } \\
\text { immunoprecipitation }\end{array}$ \\
\hline & relative \% & relative \% & relative \% \\
A-I & $60.1 \pm 5.3^{\ddagger}$ & $55.0 \pm 4.1$ & $53.1 \pm 8.2$ \\
E & $6.2 \pm 0.1$ & $8.1 \pm 0.2$ & ND $^{\xi}$ \\
A-II+Cs & $34.5 \pm 8.4$ & $37.6 \pm 3.2$ & $30.3 \pm 1.0^{\prime \prime}$ \\
\hline
\end{tabular}

* Apoprotein mass distribution was estimated by scanning densitometry after separation of $12 \%$ SDS-PAGE.

$\mp$ Values are means \pm SD of five scans of HDL from two monkeys.

${ }^{\S} \mathrm{ND}$, not determined.

" Percent radioactivity derived from apo A-II.

monkeys received an oral solution $(0.5-1.0 \mathrm{ml})$ containing $0.5 \% \mathrm{I}_{2}$ and $1 \% \mathrm{KI}$ (Lugol's solution). After injection of $200 \mu \mathrm{Ci}^{125} \mathrm{I}$-HDL into each recipient monkey, 3 -ml blood samples were collected at indicated times into tubes containing $0.05 \% \mathrm{NaN}_{3} / 0.125 \% \mathrm{~N}$-ethylmaleimide. Total radioactivity was measured in serum and in the HDL fraction after heparin$\mathrm{Mn}^{2+}$ precipitation of VLDL and LDL. Either serum or the HDL fraction were subjected to sodium cholate immunoprecipitation. Immunoprecipitable ${ }^{125}$ I-apo A-I and apo A-II, respectively, accounted for $54.0 \pm 5 \%$ and $29.9 \pm 2.4 \%$ of the total ${ }^{125}$ I-HDL radioactivity.

Fractional catabolic rates (FCR) for apo A-I and apo A-II, estimated with the cholate-immunoprecipitation method, were not significantly different from FCRs calculated using alkaline-urea PAGE to estimate radioactivity distribution (data not shown). FCRs of apo A-I and apo A-II estimated from analysis of whole serum or of HDL were also not statistically different from each other (data not shown).

Data analyses. Differences between the two dietary fat periods were analyzed by paired $t$ tests (23). The plasma disappearance curves of apolipoproteins A-I and A-II were bioexponential and were analyzed using the general principles defined by Matthews (24). The slopes $\left(b_{1}\right.$ and $\left.b_{2}\right)$ and the intercepts $\left(c_{1}\right.$ and $\left.c_{2}\right)$ were calculated by computer methods with a curve peeling program that uses least-squares analyses.

\section{Results}

As expected, rhesus monkeys had significantly lower plasma cholesterol levels when fed polyunsaturated fat (corn oil) than

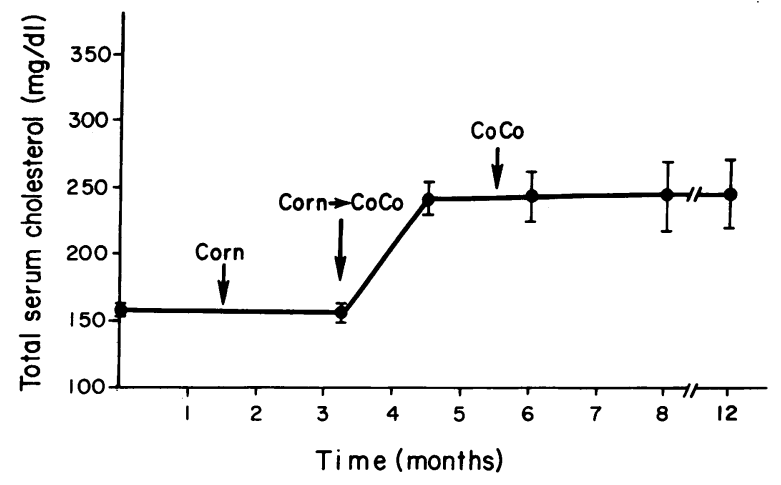

Figure 2. Plasma cholesterol response of eight rhesus monkeys fed a polyunsaturated corn oil-containing diet $(3 \mathrm{mo})$ and then a saturated coconut oil-containing diet $(9 \mathrm{mo})$. when fed saturated fat (coconut oil) (Fig. 2, Table IV). When the diet was changed from corn oil to coconut oil, the plasma cholesterol levels rose maximally within one month and remained at the level over the ensuing $8 \mathrm{mo}$ (Fig. 2). The saturated fat-induced changes in total plasma cholesterol were associated with increases in the plasma cholesterol concentration of VLDL + LDL (+ 42\%) and HDL (+ 27\%) (Table IV). Mean hydrated densities of the major lipoprotein classes, evaluated by density gradient ultracentrifugation, were not altered by diet and coconut oil feeding did not increase the quantity of intermediate density lipoproteins. Plasma triglycerides and phospholipids were also significantly higher during the saturated fat feeding (Table IV).

Lipoprotein lipid composition. The influence of dietary fat saturation on the chemical composition of VLDL, LDL, and HDL is shown in Table V. Comparisons were not based on percentage values, since the value of any one constituent is dependent on the relative amounts of all other components. Instead, statistical analyses by paired $t$ tests were performed on constituent ratios that are independent of each other.

The VLDL of rhesus monkeys fed corn oil contained a higher percentage of phospholipids and less triglyceride, free cholesterol, and cholesteryl ester than VLDL during coconut oil feeding. When examined in terms of constituent ratios, the lower free and esterified cholesterol contents were significant (Table V).

LDL during corn oil feeding contained relatively more protein and less cholesterol, phospholipid, and triglyceride than during the saturated fat diet. The constituent ratios indicated that the higher contents of free and esterified cholesterol during coconut oil consumption were significant (Table V). HDL from corn oil fed monkeys were slightly enriched in cholesteryl ester, and contained less triglyceride as evidenced by the higher CE/ PRO and lower TG/PRO ratios (Table V).

Composition of esterified fatty acids. The fatty acids of triglycerides differed most during these extreme diets, while phospholipids were least affected. The triglyceride fatty acids generally reflected the diet composition, but there were noteworthy exceptions. The proportion of 12:0 in plasma triglycerides during the saturated fat diet (Tables VI-VIII) was much less than that in coconut oil (Table II). Among the lipoproteins, the fatty acid composition of triglycerides in LDL and HDL were remarkably similar, whereas those in VLDL differed on both diets.

The medium chain fatty acids (12:0 and 14:0) found in coconut oil were not incorporated into the phospholipids of any lipoprotein class (Tables VI-VIII). Palmitic acid (16:0) accounted for 24-35\% of fatty acids in phospholipids, despite the fact that neither experimental diet was rich in palmitate (Table II). Similarly, while neither diet contained significant stearate (18:0), this fatty acid accounted for $\sim 25 \%$ of the total phospholipid fatty acid. The major effect of dietary fat saturation was on the contents of oleic (18:1) and linoleic (18:2) acids which predominate at the sn-2 position of phosphoglycerides. Corn oil feeding increased the relative amount of linoleate at the expense of oleate and larger chain fatty acids (Tables VI-VIII).

The two diets produced very different cholesteryl ester profiles. About $10 \%$ of the cholesteryl esters from coconut oil fed animals contained $12: 0$ and 14:0 fatty acids, and $\sim 40 \%$ of the total cholesteryl esters were saturated on this diet (Tables VIVIII). With corn oil feeding, in contrast, about $75 \%$ of the cholesteryl esters in LDL and HDL contained mono- or polyunsaturated fatty acids. The cholesteryl esters in LDL and HDL were generally similar and differed from those in VLDL during both diets. VLDL cholesteryl esters during corn oil feeding con- 
Table IV. Effect of Dietary Fat Saturation on Plasma Lipids, Lipoprotein Cholesterol, and Apolipoproteins

\begin{tabular}{|c|c|c|c|c|c|c|c|c|}
\hline Diet group & $\begin{array}{l}\text { Total } \\
\text { cholesterol }\end{array}$ & $\begin{array}{l}\text { HDL } \\
\text { cholesterol }^{\ddagger}\end{array}$ & $\begin{array}{l}\text { VLDL + LDL } \\
\text { cholesterol }^{\$}\end{array}$ & $\begin{array}{l}\text { Total } \\
\text { triglycerides }\end{array}$ & $\begin{array}{l}\text { Total } \\
\text { phospholipids }\end{array}$ & Apo A-I" & Apo A-II" & Apo B" \\
\hline & $m g / d l$ & $m g / d l$ & $m g / d l$ & $m g / d l$ & $m g / d l$ & $m g / d l$ & $m g / d l$ & $m g / d l$ \\
\hline Corn oil & $160 \pm 5^{\top}$ & $74 \pm 3$ & $86 \pm 4$ & $113 \pm 15$ & $334 \pm 6$ & $137 \pm 9$ & $41 \pm 3$ & $57 \pm 5$ \\
\hline Coconut oil & $250 \pm 17$ & $102 \pm 5$ & $148 \pm 11$ & $196 \pm 33$ & $399 \pm 21$ & $176 \pm 4$ & $51 \pm 3$ & $72 \pm 3$ \\
\hline$P<* *$ & 0.05 & 0.05 & 0.05 & 0.05 & 0.05 & 0.05 & 0.05 & 0.05 \\
\hline
\end{tabular}

* Esterified and unesterified cholesterol. ${ }^{\ddagger} \mathrm{HDL}$ cholesterol determined after heparin- $\mathrm{Mn}^{2+}$ precipitation. ${ }^{8} \mathrm{VLDL}+\mathrm{LDL}$ cholesterol determined as difference between whole plasma and the HDL cholesterol. "Determined by radial immunodiffusion (RID) using anti-rhesus apo A-I, A-II and LDL for six animals/group. 'Values are mean \pm SEM for eight monkeys in each group. ** Significant differences between diets determined by paired $t$ test, at least $P<0.05$.

tained much less 18:2 esters than did LDL and HDL, and VLDL cholesteryl esters during both diets were proportionately enriched in 18:0 esters.

Apoprotein concentration and distribution. Plasma apo A-I, apo A-II, and apo B levels were 23,20 , and $21 \%$ lower, respectively, in monkeys fed the corn oil diet compared to coconut oil (Table IV). $12.5 \%$ SDS-PAGE of the apoproteins of plasma VLDL, LDL, and HDL revealed no dietary fat related differences in the distribution of apoproteins in any class of lipoproteins. Therefore, only the profile from the coconut oil group is shown (Fig. 3). VLDL contained apo B and the apo A-II+C complex and LDL contained only apo B. The distribution of the HDL apoproteins, independent of diet, was: A-I, $65 \pm 4.6 \%$; E, $5.7 \pm 1.3 \%$; and A-II+Cs, $29.3 \pm 8.8 \%$. Since the degree of dietary fat saturation had no apparent effect on the isoprotein pattern of HDL, only a representative pattern from the coconut oil fed animal is shown. The isoelectric points of apo A-I isoforms were 5.9, 5.5, 5.4, and 5.3 (Fig. 4).

The apoprotein B subspecies were visualized on 3.5\% SDS gels. Both VLDL and LDL showed a single predominant apo B band ( 390,000 mol wt) (Fig. 5). There was no apparent diet effect on the apo B pattern.

Electron microscopy and column chromatography. Electron microscopy (Fig. 6) revealed no diet-related differences in size or shape of VLDL, LDL, or HDL. The diameters of plasma VLDL, LDL, and HDL were $380 \pm 15 \AA, 245 \pm 6 \AA$, and $90 \pm 4$
$\AA$ for the corn oil group, respectively, and $369 \pm 16 \AA, 248 \pm 5 \AA$, and $98 \pm 3 \AA$, respectively, for the coconut oil-fed monkeys.

The separation of plasma lipoprotein classes by agarose column chromatography is shown in Fig. 7. Peaks I, II, and III contained VLDL, LDL, and HDL, respectively, as demonstrated by agarose gel and SDS PAGE (not shown). The elution positions of the major lipoprotein classes during corn and coconut oil feeding were identical, confirming the electron microscopy finding that diet did not produce major changes in lipoprotein size.

Kinetic analyses of HDL apo A-I and A-II. Plasma pools of apo A-I and apo A-II in saturated fat-fed animals were larger than in unsaturated fat-fed animals (Table IX). The plasma radioactivity die-away curves for apo A-I and apo A-II after injection of ${ }^{125} \mathrm{I}-\mathrm{HDL}$ were typically biphasic (Fig. 8). The catabolic rates and biological half-lives of apo A-I and apo A-II did not differ from each other on the two diets. However, both apoproteins were cleared more rapidly from the plasma of the corn oil fed monkeys as reflected by greater FCRs and shorter biologic half-lives. The calculated synthetic rates of apo A-I and A-II, in contrast, were virtually identical during the two diet periods (Table IX).

\section{Discussion}

Studies in a variety of species have consistently documented that diets rich in polyunsaturated fat lower the mass of each

Table V. Effect of Dietary Fat Saturation on Composition of Plasma Lipoproteins

\begin{tabular}{|c|c|c|c|c|c|c|c|c|c|}
\hline & \multirow{2}{*}{\multicolumn{5}{|c|}{$\%$ by wt }} & \multicolumn{4}{|c|}{ Ratios of constituents (wt/wt) } \\
\hline & & & & & & \multirow{2}{*}{$\frac{\text { FC }}{\text { PRO }}$} & \multirow{2}{*}{$\frac{\mathrm{CE}}{\mathrm{PRO}}$} & \multirow{2}{*}{$\frac{\text { PL }}{\text { PRO }}$} & \multirow{2}{*}{$\frac{\text { TG }}{\text { PRO }}$} \\
\hline & $\mathrm{FC}^{*}$ & $\mathrm{CE}$ & TG & PL & PRO & & & & \\
\hline \multicolumn{10}{|l|}{ VLDL } \\
\hline Corn $^{\ddagger}$ & $3.2 \pm 0.4$ & $4.0 \pm 0.6$ & $49.6 \pm 2.5$ & $31.0 \pm 3.5$ & $12.8 \pm 0.7$ & $0.25 \pm 0.03$ & $0.31 \pm 0.06$ & $2.42 \pm 0.31$ & $3.73 \pm 0.41$ \\
\hline Coco & $6.5 \pm 0.7$ & $5.5 \pm 0.5$ & $55.6 \pm 1.0$ & $20.6 \pm 0.9$ & $12.0 \pm 1.1$ & $0.54 \pm 0.13^{8}$ & $0.46 \pm 0.05^{8}$ & $1.72 \pm 0.25$ & $5.41 \pm 0.70$ \\
\hline \multicolumn{10}{|l|}{ LDL } \\
\hline Corn $^{\ddagger}$ & $9.1 \pm 0.4$ & $30.0 \pm 1.6$ & $10.3 \pm 2.4$ & $24.6 \pm 0.5$ & $26.0 \pm 0.7$ & $0.35 \pm 0.01$ & $1.15 \pm 0.08$ & $0.95 \pm 0.04$ & $0.40 \pm 0.10$ \\
\hline Coco & $11.0 \pm 0.5$ & $25.8 \pm 1.0$ & $15.9 \pm 1.3$ & $28.0 \pm 0.9$ & $19.5 \pm 0.9$ & $0.56 \pm 0.03^{\S}$ & $1.32 \pm 0.05^{\S}$ & $1.44 \pm 0.05^{\S}$ & $0.82 \pm 0.08^{8}$ \\
\hline \multicolumn{10}{|l|}{ HDL } \\
\hline Corn & $4.0 \pm 0.3$ & $15.3 \pm 1.3$ & $8.5 \pm 1.5$ & $29.5 \pm 0.6$ & $42.7 \pm 0.8$ & $0.09 \pm 0.01$ & $0.36 \pm 0.03$ & $0.69 \pm 0.02$ & $0.20 \pm 0.04$ \\
\hline Coco & $4.0 \pm 0.2$ & $11.1 \pm 0.6$ & $11.4 \pm 0.8$ & $31.4 \pm 0.6$ & $42.0 \pm 1.0$ & $0.10 \pm 0.01$ & $0.26 \pm 0.02^{8}$ & $0.75 \pm 0.03$ & $0.28 \pm 0.02^{8}$ \\
\hline
\end{tabular}

* CE, cholesteryl ester; PL, phospholipid. ${ }^{\ddagger}$ Values are mean \pm SEM for eight monkeys on corn oil and coconut oil, respectively. ${ }^{\S}$ Significant differences between diets determined by paired $t$ test, $P$ at least $<0.05$. 
Table VI. Effect of Dietary Fat Saturation on the Fatty Acid Composition of Plasma VLDL Lipids

\begin{tabular}{|c|c|c|c|c|c|c|}
\hline \multirow[b]{2}{*}{ Fatty acid } & \multicolumn{2}{|l|}{ Phospholipids } & \multicolumn{2}{|l|}{ Triglycerides } & \multicolumn{2}{|c|}{ Cholesteryl esters } \\
\hline & $\mathrm{P}^{*}$ & $\mathbf{s}$ & $P$ & $\mathbf{s}$ & $\mathbf{P}$ & $\mathbf{S}$ \\
\hline & $\%$ & $\%$ & $\%$ & $\%$ & $\%$ & $\%$ \\
\hline 12: & $\mathrm{ND}^{\ddagger}$ & $0.4 \pm 0.2$ & ND & $19.4 \pm 6.3$ & ND & ND \\
\hline $14: 0$ & ND & $1.4 \pm 0.1$ & ND & $17.9 \pm 2.6$ & ND & $10.1 \pm 3.1$ \\
\hline $16: 0$ & $23.7 \pm 2.9^{\S}$ & $26.1 \pm 0.7$ & $21.9 \pm 3.1$ & $26.7 \pm 4.8^{\prime \prime}$ & $29.4 \pm 4.0$ & $20.4 \pm 1.3^{\prime \prime}$ \\
\hline $16: 1$ & ND & 0.3 & ND & $5.1 \pm 2.0$ & ND & $14.2 \pm 1.5$ \\
\hline $18: 0$ & $25.0 \pm 1.1$ & $22.7 \pm 1.5^{\prime \prime}$ & $3.1 \pm 0.7$ & $3.7 \pm 0.4$ & $14.4 \pm 2.2$ & $8.4 \pm 2.6^{\prime \prime}$ \\
\hline $18: 1$ & $11.1 \pm 2.4$ & $12.6 \pm 1.6$ & $30.2 \pm 3.9$ & $18.7 \pm 3.8^{\prime \prime}$ & $23.2 \pm 6.8$ & $17.4 \pm 4.9$ \\
\hline $18: 2$ & $33.7 \pm 3.5$ & $26.0 \pm 3.7^{11}$ & $44.8 \pm 6.3$ & $8.1 \pm 3.2^{11}$ & $33.1 \pm 3.5$ & $29.5 \pm 4.4$ \\
\hline \multicolumn{7}{|l|}{$>18: 2$} \\
\hline $\begin{array}{c}\downarrow \\
<20: 4\end{array}$ & $6.6 \pm 1.1$ & $10.4 \pm 1.5$ & - & - & - & - \\
\hline
\end{tabular}

* P, polyunsaturated; S, saturated diet. ${ }^{\ddagger}$ Not detected. ${ }^{8}$ Values are mean \pm SD for six monkeys in each group. "Significant differences between diets determined by paired $t$ test; $P<0.05$.

Table VII. Effect of Dietary Fat Saturation on the Fatty Acid Composition of Plasma LDL Lipids

\begin{tabular}{|c|c|c|c|c|c|c|}
\hline \multirow[b]{2}{*}{ Fatty acid } & \multicolumn{2}{|l|}{ Phospholipids } & \multicolumn{2}{|l|}{ Triglycerides } & \multicolumn{2}{|c|}{ Cholesteryl esters } \\
\hline & $\mathbf{P}^{*}$ & $\mathbf{S}$ & $\mathbf{P}$ & $\mathbf{s}$ & $\mathbf{P}$ & $\mathbf{S}$ \\
\hline & $\%$ & $\%$ & $\%$ & 9 & $\%$ & $\%$ \\
\hline $12: 0$ & $\mathrm{ND}^{\ddagger}$ & 0.3 & ND & $10.9 \pm 2.4$ & ND & $1.8 \pm 0.3$ \\
\hline $14: 0$ & ND & $2.5 \pm 0.7$ & ND & $16.7 \pm 2.9$ & ND & $7.6 \pm 1.4$ \\
\hline $16: 0$ & $30.1 \pm 3.9^{\S}$ & $34.6 \pm 8.9$ & $36.6 \pm 9.2$ & $43.4 \pm 6.7$ & $16.8 \pm 3.4$ & $23.3 \pm 5.3$ \\
\hline $16: 1$ & ND & $1.3 \pm 0.8$ & ND & $4.9 \pm 1.5$ & $2.9 \pm 0.7$ & $7.6 \pm 1.6^{\prime \prime}$ \\
\hline $18: 0$ & $28.9 \pm 2.5$ & $26.9 \pm 4.6$ & $6.2 \pm 3.1$ & $4.9 \pm 0.5$ & $4.2 \pm 2.1$ & $3.2 \pm 0.5$ \\
\hline $18: 1$ & $7.9 \pm 1.5$ & $11.5 \pm 1.6^{\prime \prime}$ & $22.6 \pm 5.0$ & $16.9 \pm 7.6$ & $25.9 \pm 6.4$ & $20.8 \pm 1.4$ \\
\hline $18: 2$ & $29.6 \pm 2.6$ & $16.5 \pm 7.5^{\prime \prime}$ & $34.3 \pm 7.3$ & $1.9 \pm 0.7^{11}$ & $50.2 \pm 8.8$ & $35.6 \pm 9.1^{\prime \prime}$ \\
\hline \multicolumn{7}{|l|}{$>18: 2$} \\
\hline $\begin{array}{c}\downarrow \\
<20: 4\end{array}$ & $3.2 \pm 0.9$ & $6.5 \pm 0.7^{11}$ & & & & \\
\hline
\end{tabular}

* P, polyunsaturated; $\mathrm{S}$, saturated diet. ${ }^{\ddagger}$ Not detected. $\quad$ Values are mean $\pm \mathrm{SD}$ for six monkeys in each group. "Significant differences between diets determined by paired $t$ test; $P<0.05$.

Table VIII. Effect of Dietary Fat Saturation on the Fatty Acid Composition of Plasma HDL Lipids

\begin{tabular}{|c|c|c|c|c|c|c|}
\hline \multirow[b]{2}{*}{ Fatty acid } & \multicolumn{2}{|c|}{ Phospholipids } & \multicolumn{2}{|l|}{ Triglycerides } & \multicolumn{2}{|c|}{ Cholesteryl esters } \\
\hline & $\mathbf{P}^{*}$ & $\mathbf{s}$ & $\mathbf{P}$ & $\mathbf{s}$ & $\mathbf{P}$ & $\mathbf{s}$ \\
\hline & $\%$ & $\%$ & $\%$ & $\%$ & $\%$ & $\%$ \\
\hline 12:0 & $\mathrm{ND}^{\ddagger}$ & 0.2 & 0.8 & $10.8 \pm 1.0^{\prime \prime}$ & ND & $2.0 \pm 0.4$ \\
\hline $14: 0$ & ND & $1.7 \pm 0.2^{8}$ & 1.2 & $17.4 \pm 1.8^{11}$ & 2.4 & $9.5 \pm 2.8^{\prime \prime}$ \\
\hline $16: 0$ & $24.7 \pm 1.0$ & $28.8 \pm 1.6^{\prime \prime}$ & $33.5 \pm 3.6$ & $46.5 \pm 5.2^{11}$ & $18.0 \pm 5.3$ & $24.1 \pm 4.8^{\prime \prime}$ \\
\hline $16: 1$ & ND & $2.3 \pm 0.3$ & ND & $4.1 \pm 1.8$ & ND & $7.7 \pm 0.7$ \\
\hline $18: 0$ & $26.1 \pm 2.6$ & $22.8 \pm 1.0$ & $5.9 \pm 1.3$ & $4.2 \pm 0.7$ & $3.5 \pm 1.4$ & $4.1 \pm 1.1$ \\
\hline $18: 1$ & $9.2 \pm 1.2$ & $13.2 \pm 1.6^{\prime \prime}$ & $18.0 \pm 2.3$ & $14.5 \pm 3.3$ & $16.8 \pm 4.6$ & $19.7 \pm 4.5$ \\
\hline $18: 2$ & $33.4 \pm 3.8$ & $23.8 \pm 1.9^{\prime \prime}$ & $40.6 \pm 6.8$ & $2.9 \pm 1.0^{\prime \prime}$ & $59.3 \pm 6.4$ & $32.6 \pm 7.0^{11}$ \\
\hline \multicolumn{7}{|l|}{$18: 2$} \\
\hline$\underset{20.4}{\downarrow}$ & $7.1 \pm 0.8$ & $7.4 \pm 1.4$ & ND & ND & ND & ND \\
\hline
\end{tabular}

* P, polyunsaturated diet; $\mathrm{S}$, saturated diet. ${ }^{\ddagger}$ Not detected. "Values are mean $\pm \mathrm{SD}$ for six monkeys in each group. "Significant differences between diets determined by paired $t$ test; $P$ at least $<0.05$. 


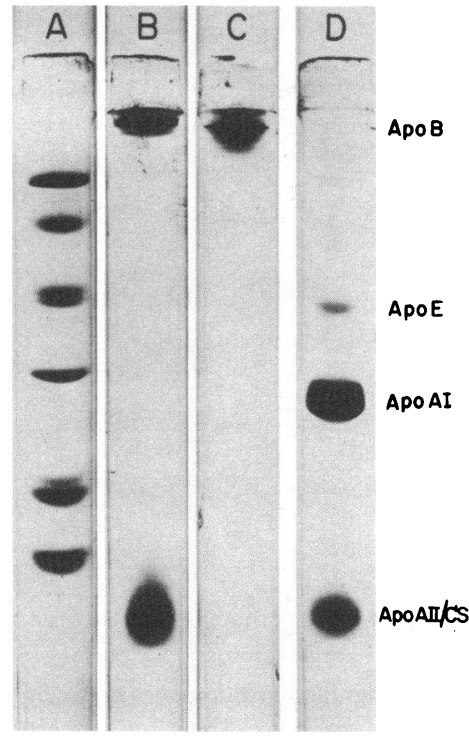

Figure 3. Representative $12.5 \%$ SDS polyacrylamide gel electrophoretogram of plasma lipoprotein apoproteins from a rhesus monkey fed a coconut oil-containing diet. Lane $A$, molecular weight standards, top-bottom, phosphorylase $\mathrm{B}$, 92,500; bovine serum albumin, 66,200; ovalbumin, 45,000; carbonic anhydrase, 31,000; soybean trypsin inhibitor, 21,500; lysozyme, 14,400. Lane $B$, VLDL. Lane $C$, LDL. Lane $D$, HDL.

lipoprotein class. There is less unanimity concerning the effects of dietary fat on the properties of lipoproteins. The monkeys studied here were fed corn and coconut oil-rich diets for 3 and 9 mo, respectively. Plasma cholesterol values were stable (Fig. 2) when analyses were undertaken, and transition effects were thereby avoided.

Dietary fat saturation and VLDL. Lower VLDL levels during corn oil feeding were reflected by the lower plasma triglyceride concentrations (Table IV). This effect may be due to selective hepatic incorporation of polyunsaturated fatty acids into phosphatidylcholine rather than triglyceride (24-26). The coconut oil based diet resulted in VLDL that were relatively enriched in both unesterified cholesterol and cholesteryl esters. Such an effect has been noted by some $(3,27)$ but not others $(28)$ who have made similar comparisons.

Dietary fat saturation and $L D L$. During polyunsaturated fat feeding, the plasma apo B level was $26 \%$ lower (Table IV) and compositional analyses showed that the LDL cholesteryl ester/ protein ratio was significantly lower than during coconut oil feeding (Table V). The latter observation suggests a greater diet

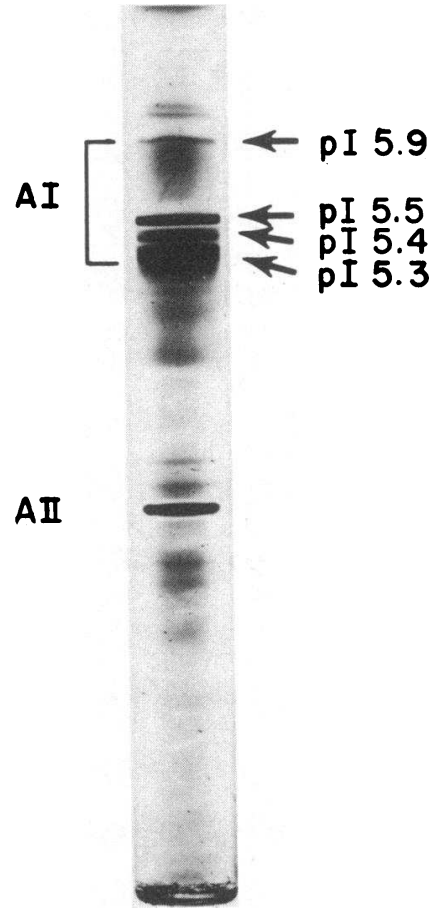

Figure 4. Analytical isoelectric focusing pattern of plasma HDL from a rhesus monkey fed a coconut oil-containing diet. Isoelectric points for apo A-I species are indicated.

effect on lipoprotein cholesterol than on apo B. Spritz and Mishkel (1) reported that a $26 \%$ fall in LDL cholesterol was attended by only a $9 \%$ fall in LDL protein; and Shepherd and co-workers (29) also found that polyunsaturated fat diets reduced the cholesterol/protein ratio in LDL. In contrast Brussard et al. (30) found no fall in the LDL cholesterol/apo B ratio when diets rich in polyunsaturated fat were consumed, and similar findings have been reported by others $(3,31,32)$. These discordant results are not easily explained and have been discussed in detail by Vega and co-workers (3).

LDL-triglyceride content was significantly greater during the coconut oil period. This is likely due to the higher total plasma VLDL and triglyceride concentrations, since LDL-triglyceride content varies directly with the plasma concentration of VLDL $(33,34)$. This relationship may be mediated by the core lipid

Table IX. Kinetic Parameters* of HDL Apo A-I and Apo A-II in Rhesus Monkeys Fed Corn Oil and Coconut Oil Based Diets

\begin{tabular}{|c|c|c|c|c|c|c|c|c|}
\hline \multirow{2}{*}{$\begin{array}{l}\text { Diet of } \\
\text { recipients }\end{array}$} & \multicolumn{2}{|l|}{ Pool size } & \multicolumn{2}{|l|}{ FCR } & \multicolumn{2}{|l|}{ Synthetic rate } & \multicolumn{2}{|c|}{ Biological half life $^{\ddagger}$} \\
\hline & $A-I^{8}$ & A-II" & $A-I^{8}$ & A-II" & A-I & A-II" & $A-I^{3}$ & A-IIII \\
\hline & $m g / k g$ & $m g / k g$ & pools $/ d$ & pools $/ d$ & mg/kg per day & mg/kg per day & $d$ & $d$ \\
\hline Corn oil & $48.4 \pm 2.5^{8}$ & $12.5 \pm 1.0^{\prime \prime}$ & $0.424 \pm 0.025^{* *}$ & $0.470 \pm 0.039^{* *}$ & $20.5 \pm 1.2$ & $5.9 \pm 0.7$ & $2.61 \pm 0.16^{* *}$ & $2.66 \pm 0.26^{* *}$ \\
\hline \multirow[t]{2}{*}{ Coconut oil } & $60.6 \pm 3.6$ & $16.0 \pm 1.0$ & $0.310 \pm 0.028^{* *}$ & $0.298 \pm 0.020^{* *}$ & $20.0 \pm 1.7$ & $4.8 \pm 0.3$ & $3.53 \pm 0.26^{* *}$ & $350 \pm 0.36^{* *}$ \\
\hline & $P<0.05^{9}$ & $P=0.05$ & $P<0.05$ & $P<0.05$ & NS & NS & $P<0.05$ & $P<0.05$ \\
\hline
\end{tabular}

\footnotetext{
* Values were calculated based on biphasic exponential die-away of radioiodinated HDL apo A-I and A-II assuming a metabolic steady state. Pool size was calculated as the plasma volume $\times$ plasma concentration of apolipoproteins A-I and A-II determined by radial immunodiffusion. Plasma volume was estimated at $4 \%$ of body weight. Synthetic rate equals the product of FCR and the pool size of apo A-I and A-II concentrations. " Biological half-life was calculated from the slopes of the second exponential. "Values are mean \pm SEM for eight monkeys. "Values are mean \pm SEM for four monkeys. ' Significance of differences between corn vs. coconut oil diet determined by paired $t$ test. ** Common superscripts indicate metabolic parameters of apo A-I and apo A-II are not significantly different from each other.
} 


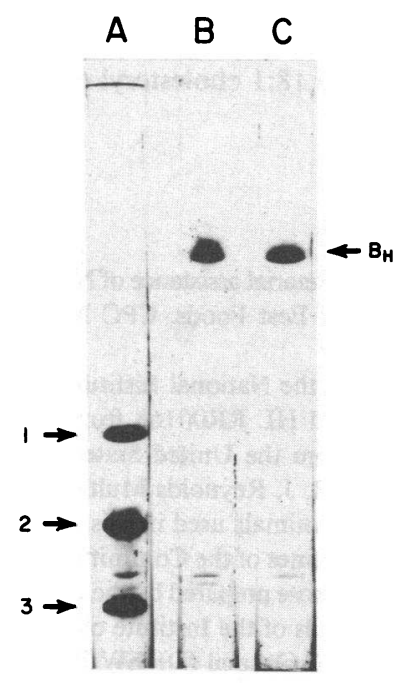

Figure 5. SDS polyacrylamide gel electrophoretograms $(3.5 \%$ acrylamide) of apoprotein B subspecies from a rhesus monkey fed coconut oil. Lane $A$, molecular weight standards: 1 = myosin, 200,000; 2 $=\mathrm{B}$-galactosidase, 116,250; and 3 $=$ phosphorylase $\mathrm{B}, 92,500$. Lane $B$, LDL showing only a single predominant apo $B$ band designated $\mathrm{B}_{\mathrm{H}}(\sim 390,000 \mathrm{~mol} \mathrm{wt})$. Lane $C$, VLDL showing one major $B_{H}$ apo B subspecies $(\sim 390,000 \mathrm{~mol} \mathrm{wt})$.

transfer protein that affects exchange of VLDL-triglyceride for LDL-cholesteryl ester $(35,36)$. Triglyceride enrichment of LDL has not been observed when saturated fat feeding has failed to significantly increase the plasma triglyceride concentration ( 3 , 28, 37).

Two studies in humans have suggested that lower LDL apo B levels during polyunsaturated fat feeding are due to lower production rates (38. 39). Other studies in humans (40) and subhuman primates (41) have suggested an effect due to enhanced catabolism. Moreover, coconut oil and cholesterol feeding reduced receptor-mediated clearance of LDL in hamsters (42) and it is possible that dietary fat saturation mediates effects through more than one mechanism.

Dietary fat saturation and HDL. We found 27\% lower HDLcholesterol levels during polyunsaturated fat feeding and levels of apo A-I and apo A-II were reduced by 28 and 24\%, respectively (Table IV). Compositional analysis showed a significantly higher cholesteryl ester/protein ratio during corn oil feeding, and this was due only in part to a substitution of cholesteryl ester for triglyceride in the HDL (Table V). Most other workers have found lower plasma apo A-I levels when diets rich in polyunsaturated fats are consumed $(4,5,42)$. Lower apo A-I/apo A-II ratios on polyunsaturate fat-rich diets have suggested a selective fall in the $\mathrm{HDL}_{2}(31)$ and a $28 \%$ fall in the $\mathrm{HDL}_{2} / \mathrm{HDL}_{3}$ ratio has been documented when polyunsaturates were substituted for saturates in the diet (4). We did not investigate $\mathrm{HDL}_{2} / \mathrm{HDL}_{3}$ changes but the ratio of apo A-I/apo A-II on corn oil (3.34) differed little from that on coconut oil (3.45).

The mechanism(s) accounting for the lower HDL levels during polyunsaturated fat feeding remains unclear. Our results suggest that the lower HDL is associated with augmented catabolism of the major HDL apoproteins in polyunsaturated fatfed animals with no dietary fat effect on synthetic rate. This finding is consistent with the results of Parks and Rudel (5) who also found higher HDL apoprotein catabolic rates in polyunsaturated fat-fed animals. However, our observations and those of Parks and Rudel (5) are discordant with the human studies of Shepherd et al. (4), demonstrating reduced synthesis of HDL apo A-I in polyunsaturated fat-fed individuals. These discrepancies may result from species or diet differences. In addition, Shepherd and co-workers studied the metabolic fate of radioiodinated apolipoproteins reconstituted with HDL rather than HDL apoprotein radiolabeled in situ.

Distribution and origin of lipoprotein neutral lipids. A comparison of the species of neutral lipids in VLDL, LDL, and HDL on these extreme diets provides insight into the extent of equilibration of lipids between lipoprotein classes. Similarities and differences depend: $(a)$ on the lipid composition of newly secreted lipoproteins; ( $b$ ) on modification by lipid active enzymes during circulation; $(c)$ on the extent of exchange and net transfer between lipoprotein classes; and $(d)$ on the turnover rates of the individual lipids and lipoproteins. When transfer and exchange are rapid relative to turnover, the species of lipids will be similar in different lipoprotein classes, irrespective of their origins. This appears to be the case with the cholesteryl esters of LDL and HDL (Table VII and VIII) although the 18:2 content of HDL during poly-
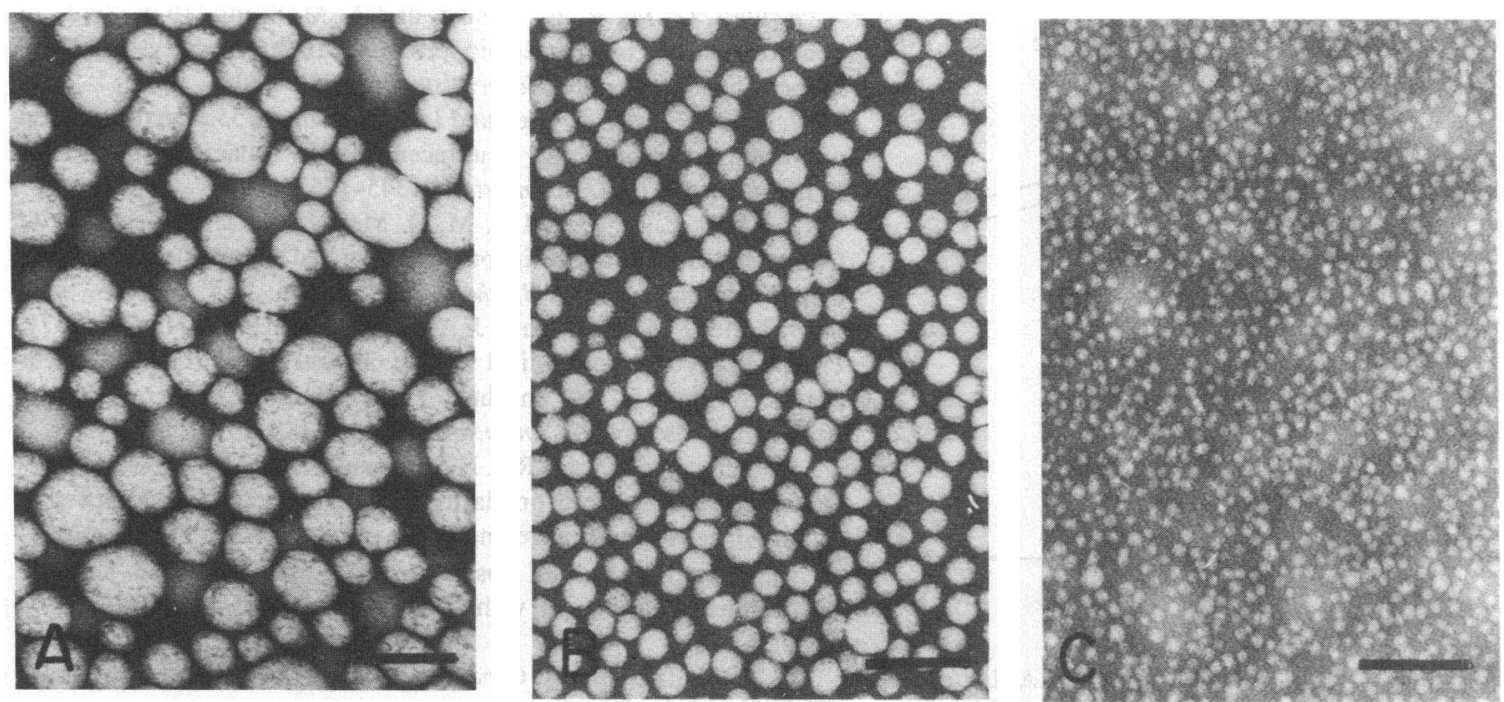

Figure 6. Electron micrographs of negatively stained (2\% sodium phosphotungstate) lipoproteins of a rhesus monkey fed coconut oil (A), VLDL

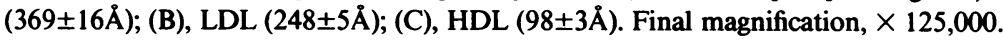




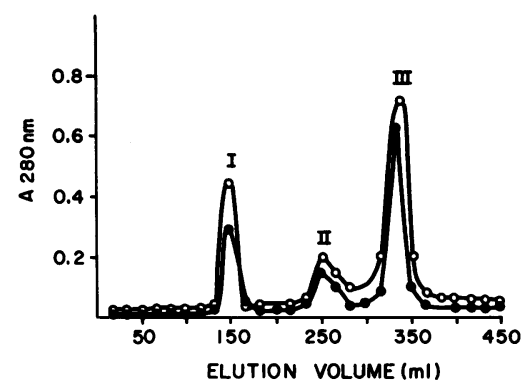

Open circles, coconut oil-fed monkey; closed circles, corn oil-fed monkey.

unsaturated fat feeding was greater than LDL. The VLDL cholesteryl esters during both diets (Table VI) contain less 18:2 and more 16:0 and 18:0 species than the cholesteryl esters in the LDL and HDL. Since VLDL are relatively short-lived compared to $\mathrm{LDL}$ and HDL, the core lipid exchange reaction probably does not complete equilibration of VLDL cholesteryl esters with the other lipoprotein classes.

The lipoprotein cholesteryl ester profiles are also of interest in view of theories concerning the origins of plasma cholesteryl esters. On both diets, $\sim 40 \%$ of the cholesteryl esters in VLDL were saturated (Table VI), and during coconut oil feeding, cholesteryl myristate (14:0) accounted for $10 \%$ of the cholesteryl esters in LDL and HDL (Tables VII and VIII). Since sn-2 fatty acids in phosphoglycerides remain unsaturated despite saturated fat feeding (1), and since virtually no 14:0 fatty acids were found in plasma phospholipids (Tables VI-VIII), the saturated cholesteryl esters likely were produced by intestine or liver rather than by the action of LCAT in plasma. Their presence in VLDL from fasting animals suggests hepatic origin, and monkey liver is known to contain acyl-CoA/cholesterol acyltransferase (43). If this reasoning is correct, then at least $40 \%$ of the plasma cho-

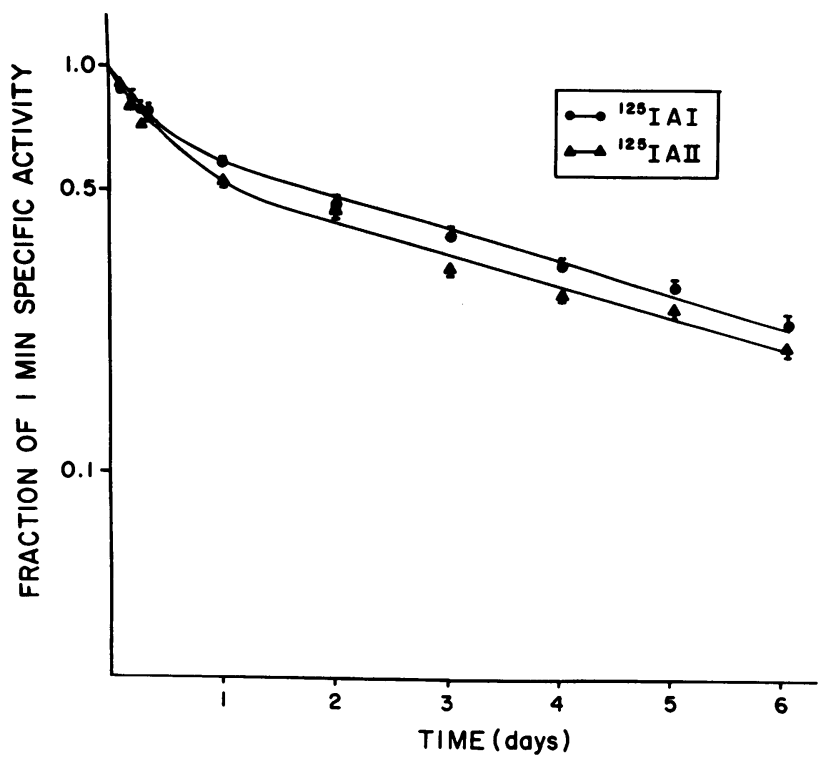

Figure 8. Typical plasma decay curves for apo A-I and apo A-II after injection of ${ }^{125} \mathrm{I}-\mathrm{HDL}$ in a rhesus monkey. Immunoprecipitation of cholate treated plasma was used to determine radioactivity associated with each apolipoprotein. lesteryl esters in coconut oil-fed animals is of intracellular origin. Moreover, at least some of the 16:1 and 18:1 cholesteryl esters are probably not produced by LCAT.

\section{Acknowledgments}

The authors would like to acknowledge the secretarial assistance of Nancy Keon. Corn oil was generously provided by Best Foods, CPC North America, Englewood Cliffs, NJ.

This work was supported by grants from the National Institutes of Health (HL 36101, HL36200, HL28467, and HL RR00168 from the Division of Research Resources), a grant from the United States Department of Agriculture (8000479) and the R. J. Reynolds Multidisciplinary Program in Cardiovascular Disease. Animals used in this study were maintained in accordance with the guidelines of the Committee on Animals of the Harvard Medical School and those prepared by the Committee on Care and Use of Laboratory Animals of the Institute of Laboratory Animal Resources, National Research Council (DHEW Publication No. [NIH] 85-23, revised 1985).

\section{References}

1. Spritz, N., and M. A. Mishkel. 1969. Effects of dietary fats on plasma lipids and lipoproteins: an hypothesis for the lipid-lowering effect of unsaturated fatty acids. J. Clin. Invest. 48:78-86.

2. Morrisett, J. D., H. J. Pownall, R. L. Jackson, R. Segira, A. M. Gotto, Jr., and O. D. Taunton. 1977. Effects of polyunsaturated and saturated fat diets on the chemical composition and thermotropic properties of human plasma lipoproteins. In Polyunsaturated Fatty Acids. R. T. Holman and W. H. Kunau, editors. American Oil Chemists Society Monograph \#4, A.O.C.S. Publishers, Champagne, IL. 139-161.

3. Vega, G. L., E. Groszek, R. Wolf, and S. M. Grundy. 1982. Influences of polyunsaturated fats on composition of plasma lipoproteins and apolipoproteins. J. Lipid Res. 23:811-822.

4. Shepherd, J., C. J. Packard, J. R. Patsch, A. M. Gotto, Jr., and O. D. Taunton. 1978. Effects of dietary polyunsaturated and saturated fat on the properties of high density lipoproteins and the metabolism of apolipoprotein A-I. J. Clin. Invest. 61:1582-1592.

5. Parks, J. S., and L. L. Rudel. 1982. Different kinetic fates of apolipoproteins A-I and A-II from lymph chylomicra of nonhuman primates. Effect of saturated versus polyunsaturated dietary fat. J. Lipid Res. 23: 410-421.

6. Fless, G. M., R. W. Wissler, and A. M. Scanu. 1976. Study of abnormal plasma low density lipoprotein in rhesus monkeys with dietinduced hyperlipidemia. Biochemistry. 15:5799-5805.

7. Havel, R. J., H. A. Eder, and J. H. Bragdon. 1955. The distribution and chemical composition of ultracentrifugally separated lipoproteins in human serum. J. Clin. Invest. 34:1345-1353.

8. Rudel, L. L., J. A. Lee, M. D. Morris, and J. M. Feets. 1974. Characterization of plasma lipoproteins separated and purified by agarosecolumn chromatography. Biochem. J. 139:89-95.

9. Forte, T., K. R. Norum, J. A. Glomset, and A. V. Nichols. 1971. Plasma lipoproteins in familial lecithin:cholesterol acyltransferase deficiency. Structure of low and high density lipoproteins as revealed by electron microscopy. J. Clin. Invest. 50:1141-1148.

10. Lichtenstein, A. H., R. J. Nicolosi, and K. C. Hayes. 1980. Dietary fat and cholesterol effects on plasma lecithin:cholesterol acyltransferase activity in cebus and squirrel monkeys. Atherosclerosis. 37:603-616.

11. Lowry, O. H., N. J. Rosebrough, A. L. Farr, and R. J. Randall. 1951. Protein measurement with the Folin phenol reagent. J. Biol. Chem. 193:265-275.

12. Weber, K., and M. Osborne. 1969. The reliability of molecular weight determinations by dodecyl sulfate-polyacrylamide gel electrophoresis. J. Biol. Chem. 244:4406-4412.

13. Menzel, H. J., R. G. Kladetzky, and G. Assmann. 1982. One 
step screening method for the polymorphism of apolipoproteins A-I, A-II and A-IV. J. Lipid Res. 23:915-922.

14. Righetti, P. G., and T. Caravaggio. 1976. Isoelectric points and molecular weights of proteins. J. Chromatogr. 127:1-28.

15. Allain, C. C., L. S. Poon, C. S. Chan, W. Richmond, and P. C. Fu. 1974. Enzymatic determination of total serum cholesterol. Clin. Chem. 20:470-475.

16. Bucolo, G., and H. David. 1973. Quantitative determinations of serum triglycerides by the use of enzymes. Clin. Chem. 19:476-482.

17. Warnick, G. R., and J. J. Albers. 1978. A comprehensive evaluation of the heparin-manganese precipitation procedure for estimating high density lipoprotein cholesterol. J. Lipid Res. 19:65-76.

18. Bartlett, G. R. 1959. Phosphorus assay in column chromatography. J. Biol. Chem. 234:466-468.

19. Herbert, P. N., L. L. Bausserman, K. M. Lynch, A. L. Saritelli, M. A. Kantor, R. J. Nicolosi, and R. S. Shulman. Homologues of the human $\mathrm{C}$ and $\mathrm{A}$ apolipoproteins in the $M$. fascicularis monkey. Biochemistry. In press.

20. Bilheimer, D., S. Eisenberg, and R. I. Levy. 1972. The metabolism of very low density lipoprotein proteins. I. Preliminary in vitro and in vivo observations. Biochim. Biophys. Acta. 260:212-221.

21. McFarlane, A. S. 1958. Efficient trace-labeling of proteins with iodine. Nature (Lond.) 182:53.

22. Ausman, L. M., and D. L. Gallina. 1978. Response to glucose loading of the lean squirrel monkey in unrestrained conditions. Am. J. Physiol. 234:R20-R24.

23. Anderson, T. W., and S. L. Sclove. 1974. Introductory Statistical Analysis. Houghton Mifflin Company, Boston, MA.

24. Matthews, C. M. E. 1957. The theory of tracer experiments with ${ }^{131}$ I-labelled plasma proteins. Phys. Med. Biol. 2:36-53.

25. Kohout, M., B. Kohoutova, and M. Heimberg. 1971. The regulation of hepatic triglyceride metabolism by free fatty acids. J. Biol. Chem. 246:5067-5074.

26. Lands, W. E. M., M. Inoue, Y. Sugiura, and H. Okuyama. 1982. Selective incorporation of polyunsaturated fatty acids into phosphatidylcholine by rat liver microsomes. J. Biol. Chem. 257:14968-14972.

27. Chait, A., A. Onitiri, A. Nicoll, E. Rabaya, J. Davies, and J. B. Lewis. 1974. Reduction of serum triglyceride levels by polyunsaturated fat. Atherosclerosis. 20:347-364.

28. Kuksis, S., J. J. Myher, K. Geher, G. J. L. Jones, J. Shepherd, C. J. Packard, J. D. Morrisett, O. D. Taunton, and A. M. Gotto. 1982. Effect of saturated and unsaturated fat diets on lipid profiles of plasma lipoproteins. Atherosclerosis. 41:221-240.

29. Shepherd, J., C. J. Packard, S. M. Grundy, D. Yeshurun, A. M. Gotto, Jr., and O. D. Taunton. 1980. Effects of saturated and polyunsaturated fat diets on the chemical composition and metabolism of low density lipoproteins in man. J. Lipid Res. 21:91-99.

30. Brussard, J. H., G. Dallinga-Thie, P. H. E. Groot, and M. B. Katan. 1980. Effects of amount and type of dietary fat on serum lipids, lipoproteins and apolipoproteins in man. A controlled 8-week trial. Atherosclerosis. 36:515-527.

31. Schonfeld, G., W. Patsch, L. L. Rudel, C. Nelson, M. Epstein, and R. E. Olson. 1982. Effects of dietary cholesterol and fatty acids on plasma lipoproteins. J. Clin. Invest. 69:1072-1080.

32. McGill, H. C., Jr., C. A. McMahan, A. W. Kruski, J. L. Kelly, and G. E. Mott. 1981. Responses of serum lipoproteins to dietary cholesterol and type of fat in the baboon. Arteriosclerosis. 1:337-344.
33. Barter, P. J., and W. E. Connor. 1975. The transport of triglyceride in the high-density lipoproteins of human plasma. J. Lab. Clin. Med. 85:260-272.

34. Carlson, L. A. 1975. Serum lipoprotein composition in different types of hyperlipoproteinemia. Adv. Exp. Med. Biol. 63:185-199.

35. Barter, P. J., L. Gorjatschko, and G. D. Calvert. 1980. Net mass transfer of esterified cholesterol from human low density lipoproteins to very low density lipoproteins incubated in vitro. Biochim. Biophys. Acta. 619:436-439.

36. Deckelbaum, R. J., S. Eisenberg, Y. Oschry, E. Butbul, I. Sharon, and T. Olivecrona. 1982. Reversible modification of human plasma low density lipoproteins toward triglyceride-rich precursors. A mechanism for losing excess cholesterol esters. J. Biol. Chem. 257:6509-6517.

37. Rosseneu, M., B. Declercq, D. Vandamme, R. Vercaemst, F. Soetewey, H. Peeters, and V. Blaton. 1979. Influence of oral polyunsaturated and saturated phospholipid treatment on the lipid composition and fatty acid profile of chimpanzee lipoproteins. Atherosclerosis. 32: 141-153.

38. Turner, J. D., N-A. Le, and W. V. Brown. 1981. Effect of changing dietary fat saturation on low-density lipoprotein metabolism in man. Am. J. Physiol. 241:E57-E63.

39. Cortese, C., Y. Levy, E. D. Janus, P. R. Turner, S. N. Rao, N. E. Miller, and B. Lewis. 1983. Modes of action of lipid-lowering diets in man. Studies of apolipoprotein B kinetics in relation to fat consumption and dietary fatty acid composition. Eur. J. Clin. Invest. 13:79-85.

40. Portman, O. W., M. Alexander, N. Tanaka, and P. Soltys. 1976. The effects of dietary fat and cholesterol on the metabolism of plasma low density lipoprotein apoproteins in squirrel monkeys. Biochim. Biophys. Acta. 45:185-196.

41. Shepherd, J., C. J. Packard, S. M. Grundy, D. Yeshurun, A. M. Gotto, Jr., and O. D. Tauntan. 1980. Effects of saturated and polyunsaturated fat rich diets on the chemical composition and metabolism of low density lipoproteins in man. J. Lipid Res. 21:91-99.

42. Spady, D. K., and J. M. Dietschy. 1985. Dietary saturated triacylglycerols suppress hepatic low density lipoprotein receptor activity in the hamster. Proc. Natl. Acad. Sci. USA. 82:4526-4530.

43. Vessby, B., J. Boberg, I.-B. Gustafsson, B. Karlstrom, H. Lithell, and A.-M. Ostlund-Lindqvist. 1980. Reduction of high density lipoprotein cholesterol and apolipoprotein A-I concentrations by a lipid-lowering diet. Atherosclerosis. 35:21-27.

44. Stokke, K. T. 1974. Cholesteryl ester metabolism in liver and blood plasma of various animal species. Atherosclerosis. 19:393-406.

45. Glomset, J. A. 1979. Lecithin:cholesterol acyltransferase. Prog. Biochem. Pharmacol. 15:41-66.

46. Balasubramaniam, S., K. A. Mitropoulos, N. B. Myant, M. Mancini, and A. Postiglione. 1979. Acyl-coenzyme A-cholesterol acyltransferase activity in human liver. Clin. Sci. 56:373-375.

47. Erickson, S. K., and A. D. Cooper. 1980. Acyl-coenzyme A. Cholesterol acyltransferase in human liver. In vitro detection and some characteristics of the enzyme. Metab. Clin. Exp. 29:991-996.

48. Goodman, D. S. 1965. Cholesterol ester metabolism. Physiol. Rev. 45:747-832.

49. Myher, J. J., A. Kuksis, J. Shepherd, C. J. Packard, J. D. Morrisett, O. D. Taunton, and A. M. Gotto. 1981. Effect of saturated and unsaturated fat diets on molecular species of phosphatidylcholine and sphingomyelin of human plasma lipoproteins. Biochim. Biophys. Acta. 666: 110-119. 